\title{
A METAFICÇÃO HISTORIOGRÁFICA E A DESSEMIOTIZAÇÃO FICCIONAL DA NARRATIVA EM MEMORIAL DO FIM: A MORTE DE MACHADO DE ASSIS
}

Rogério Lima*

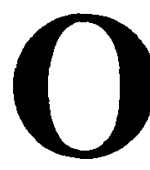

semiólogo francês Roland Barthes (1982), ao discorrer sobre o nouveau roman, ressalta, como caracteristica do tempo em que vivemos, o fato de hoje a nossa sociedade ser particularmente difícil de compreender. O homem se vê quase impossibilitado de analisar. Vivenciamos uma situação de ambigüidade, vivemos numa sociedade de classes e de massas ao mesmo tempo. Os grandes problemas da sociedade se apresentam de forma embaralhada. A própria cultura política aparece como marca de um tempo de estagnação. Como não poderia deixar de ser, esses fatores dispares influenciam a escrita e nela se traduzem.

Barthes via na escrita a arte de levantar questōes e não de responder a elas, ou de resolvê-las. Assim como o romance modemista desenvolveu essa consciência de que a literatura era a maneira de levantar questões, entendemos que o romance pós-moderno também a tenha desenvolvido. Até a formulação dessa tese, a literatura não havia posto em dúvida o sentido das coisas. Isso quer dizer que, neste caso, a totalidade do que nos rodeia pode ser um acontecimento ou mesmo um objeto. A literatura tem como função levantar esse questiona-

* Universidade de Brasilia. 
mento por intermédio da narrativa, do romanesco ou da personagem. Dessa forma, a questão do sentido tornou-se fundamental para que se possa entender o romance pós-moderno.

Na pós-modernidade, a linguagem passou a ser a grande fonte doadora de subsídios para a construção de uma nova linguagem na arte. Com o impasse a que chegou o modernismo após alcançar o seu lugar no Museu, não restou grande coisa a se elaborar em termos de linguagem. Eis que surge então o pós-moderno, não como proposição salvadora, como criador de uma nova linguagem, mas como reelaborador de todos os signos construídos e cristalizados pelo modernismo, e não só por ele.

A pergunta que formulamos em nosso trabalho e à qual procuramos responder é a seguinte: por meio de que artifícios se constrói o sentido no romance da pós-modernidade? Entendemos que essa possa ser a questão levantada pela literatura pós-moderna. De certa maneira, estamos bastante próximos da pergunta formulada pelo nouveau roman: "será que as coisas significam alguma coisa?"

Para entendermos como funciona o pós-moderno e a narrativa da pósmodernidade lançamos mão da obra intitulada Poética do pós-modernismo: história, teoria, ficção, de autoria da pesquisadora norte-americana Linda Hutcheon. E tomamos como ponto de partida para a elucidação das questões levantadas em nosso trabalho a sua proposição teórica intitulada de metaficção historiográfica. Com esse termo, Hutchcon se refere a romances famosos e populares que, simultaneamente, são veementemente auto-reflexivos, e ainda assim, de modo paradoxal, se aproximam de acontecimentos e personagens históricos. $O$ nome da rosa, de Umberto Eco, é um dos maiores exemplos de metaficção historiográfica.

Na maioria dos trabalhos de crítica sobre o pós-moderno, é a narrativa - seja na literatura, na história, ou na teoria - que tem constituido o principal foco de atenção. Esses três domínios são incorporados pela metaficção historiográfica. A autoconsciência teórica acerca da história e a ficção como realizações do homem tornam-sc o alicerce para o seu "repensar e sua elaboração das formas e dos conteúdos do passado". É importante estar atento para o fato de este tipo de realização ficcional já ter sido percebido várias vezes pelos críticos, $\mathrm{c}$ de a sua natureza paradigmática não ser levada em consideração: normalmente ela é classificada em termos de outra coisa - por exemplo, como "meia ficção", ou como "paramodernista". Essa classificação é outra particularidade da essência contraditória que está, por natureza, inseparavelmente ligada à metafíç̧ão historiográfica, pois conforme aponta Hutcheon, ela sempre age "dentro das convenções a fim de subvertê-las". A metafiç̧ão historiográfica não é somente metaficcional, nem mais uma versão do romance histórico ou do romance não-ficcional. 
Analisando os debates produzidos pela crítica cultural, é possível chegar à seguinte conclusão: atualmente, na cultura ocidental, o pós-moderno se configura, no mínimo, como uma força problematizadora: ele levanta questōes sobre (ou torna problemáticos) o senso comum e o "natural". Mas nunca oferece respostas que ultrapassem o provisório e o que é contextualmente determinado (e limitado).

Tachado de anistórico e desistoricizado, o pós-modernismo não é nostálgico nem saudosista em sua reavaliação critica da história. Ao avaliar a relação entre discurso histórico c literário, a metafiç̧ão historiográfica levanta questões relacionadas com forma narrativa, intertextualidade, estratégias de representação do real ficcional, função da linguagcm, a relação do fato histórico com o acontecimento empírico e as conseqüências epistemológicas e ontológicas do ato de tornar problemático aquilo que antes cra aceito pela historiografia - c pela literatura - como uma certeza.

O romance pós-modemo problematiza em vez de demolir. Subverte as noções de sujeito desafiando o pressuposto humanista de um $E u$ unificado e uma consciência integrada, através da instituição da subjetividade coerente. O que está sendo posto em discussão pelo pós-modemismo são os princípios da nossa ideologia dominante, a qual damos o nome de humanista liberal: este questionamento abrange desde a noção de originalidade e autoridade autoral até a separação entre o estético e o político.

O pós-modernismo, na sua relação com a ideologia, transmite a seguinte lição: todas as práticas culturais são portadoras de um subtexto ideológico que fixa as condições da própria possibilidade de sua produção ou de seu sentido. $\mathrm{E}$, na arte, cle o realiza expondo as contradições entre auto-referência e sua fundamentação histórica. É importante estar atento para o fato de essas contradiçōes nem sempre estarem visivcis.

Sem esconder a sua condição contraditória, a cultura pós-moderna usa até ao extremo as convenções do discurso. Ela sabe que não pode escapar ao envolvimento com tendências económicas (capitalismo recente) e idcológicas (humanismo liberal) de seu tempo. Não há saida. Tudo o que ela pode fazer é questionar a partir de dentro. Ela só pode problematizar aquilo que Barthes chamou de "dado" ou de "óbvio" em nossa cultura.

O questionamento pós-moderno está voltado para noçōes que em diferentes momentos afiguram-se como "naturais", de modo que não produzem nenhuma hesitação ou perplexidade, por estarem integradas ao senso comum. Essas noções são: a História, o $E u$ individual, a relação da linguagem com seus referentes e dos textos com outros textos (intertextualidade). O que o pós-moderno produz ao elaborar esse questionamento é um desafio interno à cultura, sem contudo implodi-la. 
Como contribuição para a discussão teórica do pós-moderno, formulamos a tese de que o mesmo, longe de ser um mero repetidor de estilos mortos - tal como o acusa Fredric Jameson - realiza na verdade o que denominamos de dessemiotização dos signos da cultura. Por dessemiotização entendemos o esvaziamento que sofrem os signos cristalizados da cultura e seus significados para serem utilizados somente como signos lingüísticos.

O pós-moderno elabora o seu código a partir da própria linguagem, e busca na cultura os signos que irāo constituir o seu discurso. Para demonstrar o processo de dessemiotização do signo, utilizamos em nossa pesquisa a obra Memorial do fim: a morte de Machado de Assis, de Haroldo Maranhão. $\mathrm{O}$ romance de Maranhão foi totalmente construido a partir das lembranças que o autor possuia dos signos cristalizados da obra machadiana, ele é resultante de um amor que remonta à sua adolescência.

Todas as personagens de Memorial do fim, apesar de terem como referência a obra de Machado de Assis, em nada mais se ligam a ela. O Conselheiro Ayres, Machado de Assis, Lobo Neves, Brás Cubas, Marcela, Dona Carmo, Aguiar e Fidélia só existem enquanto signos, pois foram todos dessemiotizados. O processo de dessemiotização pelo qual passaram essas personagens resulta numa nova condição, a condição de signo puro, signo este que será estruturado de uma nova forma pelo pós-moderno.

O trabalho que o pós-moderno realiza é um trabalho de descodificação, que produz uma recolocação dos elementos do discurso literário dentro de uma nova economia ficcional. No romance pós-moderno os elementos do discurso romanesco são reagrupados como linguagem, como signos, livres de qualquer outra refcrência.

Tomando a noção de signo como aquilo que está no lugar de alguma coisa c entendendo que todo signo está carregado de uma intenção de comunicação, chegamos à conclusão de que o signo pós-moderno, longe de ser um mero pastiche que supera a paródia, conforme o classifica Fredric Jameson (1993, p. 27), ć na realidade uma produção que reorganiza os sentidos do discurso ficcional na pós-modernidade.

É possível fazer uma comparação entre Memorial de Ayres, de Machado de Assis, e Memorial do fim, de Haroldo Maranhão, e constatarmos que Machado de Assis exprimia em suas obras uma sociedade definida e bem estruturada, característica do scu tempo. O romance machadiano significava um real, um real com uma saudade do passado, por isso é possivel constatar a freqüência da memória em seus textos.

Em Memorial do fim não há uma representação da sociedade de forma definida: o que ocorre ao longo de todo o romance é um constante entrecruzar entre o real histórico e o real ficcional. Não há propriamente uma história sendo contada - o que torna difícil resumir a trama da narrativa. Esse é um dos pontos 
irônicos da narrativa, que apresenta diversos outros, como o próprio título que nos promete a narrativa da morte de Machado de Assis, contrariando, dessa forma, os estatutos biográficos: a vida cede lugar à morte, que passa a ocupar o lugar de objeto de enfoque. Em Memorial do fim uma das múltiplas vozes narrativas narra os momentos pré-agônico c agônico do grande autor e/ou do personagem-narrador do último romance de Machado de Assis, Memorial de Aires, o Conselheiro Aires. No correr da narrativa percebe-se que ora é Machado de Assis que agoniza, ora é o Conselheiro Aires.

Todo signo é um signo de: Aires é um signo da obra machadiana, mas em Memorial do fim o signo Conselheiro, enquanto integrante de uma realidade ficcional pós-modema, anula o seu referente, assumindo dessa maneira a condiçāo de signo do signo.

Toda lembrança é ficcionalizante. Tomando essa afirmação como um dos pontos da nossa tese, é possível aceitar a recuperação da memória em Memorial do fim como um processo de reficcionalização, resultado da dessemiotização do texto machadiano. Ao passar pelo processo dessemiotizador (desficcionalização), os signos da obra machadiana são liberados da condição de signos de e realocados dentro de uma nova ordem ficcional (reficcionalização). $O$ texto machadiano só pode ser recuperado enquanto linguagem, c como toda recuperação é ficcionalizadora, é possivel concluir que essa é uma recuperação dessemiotizadora.

Os paradoxos da teoria pós-moderna e de sua prática se posicionam no interior do sistema e mesmo assim agem com o objetivo de possibilitar que as premissas desse sistema sejam consideradas como ficçōes ou como estruturas ideológicas. Isso não invalida o seu valor de "verdade", mas determina as condições dessa "verdade". Esse tipo de processo revela os percursos dos sistemas significantes que constituem nosso mundo - um mundo formado por sistemas construídos com a finalidade de atender às nossas necessidades.

No universo pós-modernista cabe às palavras a função de inventoras do nosso mundo. Elas enformam o mundo. Tornaram-se a única justificativa para o nosso mundo. Apoiado nisso é que o pós-modernista continua a produzir o seu discurso, ainda que tenha consciência de que não pode mais do que recuperar significados cristalizados. $O$ trabalho elaborado com os signos cristalizados revela uma consciência de que o contex to social é formado de palavras e de que todo novo texto tem suas bases assentadas sobre um texto anterior. A relação entre o texto $\mathrm{e}$ o código $\mathrm{e}$ conseqüentemente a ênfase no código se mostra mais clara que no texto modernista. Uma das questões surgidas a partir desse centramento no código é a de como a forma de contar uma história tornou-se mais importante que a própria história. Isto aplica-se, inclusive, à obra que é objeto de nosso estudo, Memorial do fim. Em diversas passagens da obra o código ficcional é posto em discussão: 
Certas pessoas assentaram que livros lesam mais que alimentam. Prefiro não opinar, ao menos por ora. Não me proponho a descer às camadas mais fundas da questão. $O$ tédio não me animaria os braços a cavar; sem considerar-se que do esburacar do chão, sendo ele farelento, resulta poeira, e poeira afeta o nariz, e nariz a fetado pela poeira espalha espirros e perdigotos. Livros sāo bem quistos e malquistos, restando saber em que proporçōes. Ora, ponhamos cobro aos círculos concêntricos, ao redor da cova onde se sepulta o mistério essencial dos livros. (MARANHAO, 1991, p. 75)

No código pós-modemista, o leitor ocupa um papel fundamental, ganha maior realce do que no modernismo. Constantemente, o texto estabelece com ele uma interlocução, dá-lhe instruções, coloca-lhe questões. Na possibilidade de existéncia de finais múltiplos, o leitor tem autonomia para se decidir pelo caminho que melhor lhe satisfaça, ainda que se espere dele um comportamento mais de acordo com o código do emissor ao optar pela não-preferéncia.

Esses elementos apontados como característicos do pós-moderno, arrolados aqui, servem para demonstrar a forma como eles exercem sua funçāo dessemiotizadora das intertextualizações (fatos, personagens, contextos), a fïm de utilizá-los apenas como linguagem instauradora, numa nova associação sintagmática, para a criação de uma nova proposição de realidade ficcional.

No caso de Memorial do fim, a manipulação das várias personagens machadianas e dos diferentes contextos, inclusive a figura do próprio Machado, seus amigos $\mathrm{c}$ o contexto histórico, instaura uma total ambigüidade no universo ficcional machadiano, permitindo recuperá-los como linguagem (signos lingüísticos comuns), para a criação de uma nova proposição de realidade ficcional.

Os modernistas estruturavam as suas proposições de realidade ficcional a partir de mundos concebíveis e possíveis; os pós-modernistas escrevem sobre mundos concebiveis, ao menos imagináveis, porém irrealizáveis, impossíveis, mundos que só encontram possibilidade de concepção na nossa imaginação. $O$ termo impossivel está referenciado por uma impossibilidade empírica fundada na nossa experiência de mundo, como nos chama a atenção Douwe Fokkema (s.d., p. 82). Essa é uma das características do processo de dessemiotização que o pós-moderno realiza em relação ao modernismo.

Desdobramento de uma mesma realidade, modernidade, modernismo $\mathrm{e}$ pós-modernismo diferem fundamentalmente num ponto básico: o tempo. $O$ modernismo vivenciou uma conquista antecipada do futuro, o que significa dizer que ele viveu no presente ofuturo antecipado, enquanto o pós-modernismo vive 
no presente o passado sido. Isto porque o presente pós-moderno é o futuro moderno antecipado que, por já ter sido experimentado, é passado.

Quando o acontecimento - que deve se entendido, semiologicamente, como o fato ou a ação que irrompe na narrativa colocando em confronto o espaço e a personagem - assume seu próprio investimento lógico, ele se liberta da apreensão racionalizante das razões objetiva e subjetiva e conseqüentemente é declarado irracional, absurdo, sem sentido e louco. Baseados nessa formulação, podemos concluir que a imagem de mundo da modernidade, sob o efeito da ação organizadora da lógica factual, que funciona como princípio racionalizante da razão objetual, funda-se como uma realidade que o homem não pode moldar, que não o fundamenta nem o integra, daí ser percebida como desprovida de sentido e absurda.

Anazildo Vasconcelos da Silva (1992) argumenta que para a modernidade essa nova condição racionalizante representa o estabelecimento de uma nova razão humana que traz consigo o poder de estabelecer as bases de uma nova consciência universal, integradora de uma nova condição humano-existencial.

A partir do estabelecimento dessa nova condição existencial, tudo que for percebido como estranho, seja loucura ou absurdo, desprovido de sentido, passa a ser considerado como moderno. Dessa forma, o modernismo, na condição de primeiro estruturador da modemidade, impòs a nova condição racionalizante da imagem de mundo por meio de estruturas arquetípicas de representação histórica e organizadoras do caos.

Com a ordenação do caos, submetido à racionalização estrutural, o modernismo elaborou a sua representação de mundo. Representação esta, como vimos anteriormente, fundada a partir da idéia de mundos concebiveis e possíveis, mas que se encontrava aquém do novo mundo planejado.

Para Vasconcelos da Silva, a ordenação do caos operada pelo modernismo não representou a imposição de uma nova ordem ao caos, a moldagem do caos, imprescindivel para o engendramento de um novo mundo. Essa ordenação representou na verdade apenas uma contenção do caos. Porém, a manipulação do tempo não possibilitou essa visão porque o mundo representado historicamente era of futuro antecipado, enquanto, ao mesmo tempo, o princípio reificante do caos submetia o presente abstraido. Somente na segunda etapa da modernidade, com o estabelecimento do pós-modernismo, é que a racionalização estruturada será denunciada como conseqüència de uma razão não-humana. O modernismo perde a sua força, o seu jogo estrutural já não é mais percebido como absurdo ou sem sentido. $O$ código modernista caiu no domínio público: daí o scu esvaziamento, sua cristalização e sua accitação no museu e, conseqücntemente, a sua acomodação como arte domada. 
A segunda etapa da modernidade estabelece-se por meio do mesmo processo da primeira, a partir do princípio reificador do caos. O pós-modernismo, enquanto estruturador da segunda etapa da modernidade, impõe, evocando o nome de uma razão humana, a liberação do caos, a partir da denúncia da racionalização estrutural e de uma necessidade de implosão dessas mesmas estruturas, gerando, dessa forma, uma vivência do caos, pois só essa vivência é capaz de humanizá-lo, dotando-o de uma nova consciência humana. Apenas por intermédio da vivència do caos é que é possivel humanizá-lo e, como conseqüência desse processo, se estabelece a possibilidade de transformá-lo em matéria humana, na origem de uma nova consciencia humana. Por isso, o forte antiempirismo e a construção de mundos concebiveis, imagináveis, porém impossíveis, que só encontram lugar de sustentação na nossa imaginação. Mundos dessemiotizados que irão se estruturar a partir de uma nova realidade que é a realidade da linguagem.

Concluindo, podemos dizer que a linguagem, na pós-modernidade, estrutura-se como mundo doador de signos que, organizados por meio do discurso ficcional pós-moderno, adquirem uma significação livre de qualquer elo referencial. Esses signos irão compor esses mundos imagináveis e possiveis dentro da nossa imaginação, mas não só aí, pois o processo da dessemiotização, ao realocar os signos, torna o mundo possivel dentro do próprio universo da linguagem.

Pretendemos com esse trabalho iluminar alguns indices que se reportam à questão da construção do sentido no discurso ficcional dentro da estética do pós-modernismo. Tratamos, pois, de questões relativas ao entrecruzamento que ocorre entre a realidade histórica e a realidade ficcional. $O$ que resta desse entrecruzamento são signos que só podem ser recuperados como signos lingüisticos, signos esvaziados de qualquer outro sentido que não o da própria linguagem.

A crítica tem se referido ao pós-modemo como um pastiche de estilos mortos, um museu de grandes novidades. Na nossa pesquisa buscamos analisar se essa afirmação é verdadeira. É em uma narrativa pós-moderna, Em liberdade, de Silviano Santiago, que é possivel encontrar uma definição do passado que é bastante útil no que diz respeito ao uso que faz dele o pós-moderno:

O passado é apenas um lugar de reflexão que o homem presente pode escolher (ou não) para melhor direcionar a sua posição no hoje e no amanhã. Sendo o lugar da reflexão, o passado não tem um valor em si que deve ser preservado a todo custo, mas pode e deve ter um valor que the é dado pelo horizonte das expectativas do presente. (SANTIAGO, 1994, p. 85) 
Concordamos com o sentido de pastiche, pois entendemos que o passado vivenciado hoje foi na realidade o futuro do nosso presente, vivenciado no presente do modemismo. Concordamos com a antecipação temporal, pois tendo o modemismo vivido o futuro no presente, pouco ou nada deixou para ser experimentado no nosso presente. Restou-nos então um arsenal cultural cristalizado que é vasculhado com o auxilio da memória, memória fragmentada $e$ fragmentária, que revolve o passado em busca de signos para serem realocados, dessemiotizados. Com esse processo, o pós-moderno abriu mão da sensação de ter chegado tarde no mundo e da sensação de que tudo já tinha sido feito. A sua postura é a de dessignificar, desficcionalizar para poder ficcionalizar a partir de uma nova lógica que não comporta mais a visão de mundo modernista.

Considerando que o fato de dessemiotizar constitui uma criação, o pós-modernismo, manipulando a herança cultural através do pastiche e da intertextualidade, instaura uma nova condição de produção de signos, estabelecendo uma nova relação do homem com o mundo. O seu projeto é claborado com a finalidade de problematizar e subverter questöes que dizem respeito a noção de sujeito, contestando a noção de um $E u$ unificado e uma consciència integrada por meio de uma subjetividade coerente. A cultura pós-moderna ć portadora de uma consciência de que é impossivel escapar ao envolvimento com tendéncias económicas e ideológicas de seu tempo. Ela só pode problematizar o dado e o óbvio em nossa cultura, dai o seu envolvimento com o passado.

O pós-moderno, por não ter o seu código ainda sob domínio público, apesar de estarmos convivendo com ele há pelo menos quarenta anos, ainda é visto com desconfiança. A nossa pesquisa sustenta que essa utilização do passado, longe de ser uma utilização negativa, de pura citação, é na verdade a produção de uma nova proposta de elaboração ficcional.

Embora tendo limitações geográficas, nada impede que o pós-moderno, pelo menos no mundo ocidental, seja aceito como movimento estético que veio para ficar até que um novo estilo venha destroná-lo. Mas para que isso ocorra será necessário que se tenha alcançado o domínio do seu código: somente a partir da total apreensão do código pós-moderno é que ele poderá ser decretado um estilo morto.

\section{RESUMO}

Este trabalho apresenta algumas reflexões sobre o processo de estruturação do signo literário no código pós-moderno. A questão fundamental que se propõe é a seguinte: como se constrói o sentido da narrativa ficcional na pós-modernidade? Observando a organizaçăo do real histórico e do real ficcional em Memorial do fim: a morte de Machado 
de Assis, de Haroldo Maranhão, é possivel constatar que o pós-moderno dessemiotiza os signos cristalizados da cultura para realocá-los sob uma nova estrutura significativa.

Palavras-chave: romance moderno; pós-modernismo; Haroldo Maranhāo.

\section{ABSTRACT}

This work develops some reflections about the strutucturation of the literary sign in postmodern code. The fundamental question is: how is the sense of fictional narration built in the Postmodern period? By observing the organization of the historic reality and of the fictional reality in O memorial do fim: a morte de Machado de Assis, by Haroldo Maranhão, it's possible to conclude that Postmodernism dessemiotizises consolidated cultural signs in order to replace them by a new significative structure.

\section{REFERÊNCIAS BIBLIOGRÁFICAS}

ASSIS, Machado de. Memórias póstumas de Brás Cubas. São Paulo: Moderna, 1994. (Coleção Travessia) . Memorial de Aires. São Paulo: Círculo do Livro, 1978.

BARTHES, Roland. O grāo da voz: entrevistas 1962-1980. Lisboa: Edições 70, 1982. (Coleção Signos, 37)

FOKKEMA, Douwe W. História literäria, modernismo e pós-modernismo. Tradução: Abel Barros Baptista. Lisboa: Vega. [s.d.] (Coleção Vega Universidade).

HUTCHEON, Linda. Poética do pós-modernismo: história, teoria, ficção. Tradução Ricardo Cruz. Rio de Janeiro: Imago, 1991. (Série logoteca)

JAMESON, Fredric. O pós-modernismo e sociedade de consumo. In $O$ mal-estar no pós-modernismo. Rio de Janeiro: Jorge Zahar Editor, 1993.

MARANHÃO, Haroldo. Memorial do fim: a morte de Machado de Assis. São Paulo: Marco Zero, 1991.

SANTIAGO, Silviano. Em liberdade. Rio de Janeiro: Rocco, 1994.

SILVA, Anazildo Vasconcelos da. O pós da modernidade. Revista das FIVA, Rio de Janeiro, Faculdades Integradas Veiga de Almeida, v. 1, n. 1, p. 13-17, jan./jun. 1992. 